\title{
ABRANGÊNCIA DA ATUAÇÃO DO ENFERMEIRO EM SALA DE RECUPERAÇÃ̃O ANESTÉSICA COMO PERSPECTIVA DE MELHOR ASSISTÊNCIA AO PACIENTE NO PERÍODO PERIOPERATÓRIO
}

Aparecida de Cássia Geani Peniche*

PENICHE, A.de C.G. Abrangência da atuação do enfermeiro em sala de recuperação anestésica como perspectiva de melhor assisténcia ao paciente no período perioperatório. Rev.Esc.Enf.USP, v. 29, n. 1, p. 83.90 , abr. 1995.

A área de atuação do enfermeiro em sala de recuperação anestésica (SRA) mostra uma abrangência, não só a nível assistencial como também na área educacional, de pesquisa e administrativa que devem ser exploradas em nosso país com o objetivo de melhor assistir o paciente no periodo perioperatório.

UNITERMOS: Sala de recuperação anestésica. Atuação da enfermeira em sala de recuperação anestésica.

Em 1904 foi designado uma área, próxima às salas de operações, em um centro cirúrgico de Boston. A idéia era de que todo paciente, submetido a cirurgia abdominal, com possibilidade de apresentar vômito, distenção abdominal ou desconforto anestésico fosse para esse local, onde a enfermeira administraria os cuidados necessários até a estabilidade dos sinais vitais e retorno da consciência (FRANKLIN; FRAULINI, 1987).

$\mathrm{E}$ assim outras especialidades foram designando seus pacientes a áreas especificas para cada tipo de cirurgia, porém em locais diferentes, com a intenção também de proteger, poupar outros pacientes, não cirúrgicos, do "acordar da anestesia".

Até o início de 1940 a unidade de cuidados pós-operatórios não existia. Segundo FRANKLIN; FRAULINI (1987) a idéia de uma área onde se concentrasse pessoal e equipamento, para esse fim, não era concebida devido a 3 razões:

\footnotetext{
* Enfermeira. Assistente do Departamento de Enfermagem Médico-cirúrgica da Escola de Enfermagem da USP.
} 
- tipos de agentes anestésicos disponíveis eram limitados e seus efeitos colaterais não justificavam a existência de uma unidade especializada para atender o paciente.

- tipos de procedimentos cirúrgicos eram simples.

- número elevado de enfermeiras, justificado, no período da II Guerra Mundial, pela existência de escolas de enfermagem vinculadas a hospitais que utilizavam o estudante remunerando-o mal e sobrecarregando-o nas atividades, além de disporem de enfermeiras privadas para assistir os pacientes.

Foi com utilização de drogas causadoras de profunda depressão respiratória e com a realização de cirurgias torácicas que a unidade de recuperação anestésica obteve o perfil que possui atualmente, podendo contar com número de enfermeiras treinadas, com a centralização de equipe e equipamentos necessários para prestar assistência aos pacientes emergindo da anestesia (NOCITE, 1987).

Segundo FRAULINI (1987) pouco se tem escrito sobre o desenvolvimento da enfermagem em sala de recuperação anestésica como especialidade, o que não deixa dúvida da sua complexidade de ação devido à existência de cuidados especializados a pacientes submetidos aos avanços técnicos e farmacológicos.

Pela existência dessa complexidade de ação poderíamos fazer uma analogia com as áreas de atuação da enfermeira proposta por MINZONI (1980), e as possibilidades da enfermeira atuar em SRA, não só na área assistencial e administrativa em toda extensão, como também abranger as áreas da educação e da pesquisa, tendo-as como perspectiva de melhor assistência ao paciente.

Atualmente com a internação do paciente feita no mesmo dia da realização da cirurgia, aumenta-se a necessidade de orientações e esclarecimentos feitos pela enfermeira ao paciente e sua família quanto aos preparos relacionados aos cuidados pré-operatórios específicos; tipo de procedimento anestésico-cirúrgico a ser realizado e período pós-operatório, incluindo desde o momento de sua permanência em SRA até a alta hospitalar. Como cita LITWACK, (1989) a atividade educacional da enfermeira de SRA não só inclui a orientação do paciente e sua família como também a educação continuada e a formação do pessoal auxiliar de enfermagem, orientação aos graduandos de enfermagem que têm a possibilidade de desenvolver estágios curriculares nessa área. (FARMER, 1985; LITWACK, 1989).

Com a busca de melhor assistência de enfermagem ao indivíduo a área administrativa vem sendo mais trabalhada, juntamente com a assistencial em SRA, uma vez que as atividades de planejamento e organização, coorde- 
nação, supervisão e avaliação visando à otimização, não s6 das condições ambientais mas permitem a efetivação da assistência onde a habilidade de relacionamento interpessoal é necessária para o desenvolvimento efetivo do trabalho com a equipe de enfermagem, cirurgiões e outros profissionais envolvidos na área de recuperação anestésica. (LITWACK, 1989)

Assim acreditamos que as atividades administrativas e gerenciais do enfermeiro em SRA veêm se desenvolvendo com certa facilidade pela própria dinâmica dessa unidade, onde os intervalos de tempo, sem a presença do paciente, possibilitam o planejamento, organização, coordenação, supervisão e avaliação.

Para os autores já citados, a enfermeira de SRA tem procurado uma mobilidade de atuação com o objetivo de solucionar os problemas encontrados em sua prática diária, e a área da pesquisa, acredito ser, um caminho a ser explorado, principalmente em âmbito nacional para se atingir esse fim.

Segundo BIANCHI et al (1988) a realização de pesquisas e sua conseqüente divulgação e publicação requer um esforço do profissional no sentido de desenvolver o seu lado de pesquisador, como também pressupõe a oferta de recursos materiais e financeiros nem sempre disponíveis em nossa realidade.

A escassez de relatos de pesquisa em SRA, pode ser agravada pelas características do trabalho do enfermeiro, que tende a dedicar seu tempo, quase que integralmente, na assistência direta ao paciente, onde na maioria das vezes encontra-se numa fase bastante delicada e de risco de vida, ficando muitos problemas ao meu entender identificados, porém não pesquisados.

A realização de pesquisas parece ser um mito entre as enfermeiras assistenciais colocando a elaboração do trabalho científico como tarefa exclusiva do enfermeiro docente.

Embora, NOGUEIRA (1989) relate que tenha havido um avanço em meados dos anos 70, decorrente da expansão dos cursos de graduação e pósgraduação, influenciado pela própria evolução da enfermagem, essa relação resulta na não operacionalização das pesquisas uma vez que, são produzidos por enfermeiras vinculadas à docência e percebidas, enquanto problema, por enfermeiras-assistenciais. Não havendo continuidade em termos de avaliação, reformulação e geração de novas pesquisas.

Em levantamento bibliográfico feito $\mathrm{cm}$ âmbito nacional por docentes da disciplina de enfermagem em centro cirúrgico, em um período de 10 anos (1982 a 1992) por ocasião do Encontro Internacional "Pesquisa em Enfermagem: uma questão de saúde" promovido pela Escola de Enfermagem da USP, obteve-se um total de 20 pesquisas na área de recuperação anestésica sendo, na maioria, produzida em decorrência de eventos específicos e curso de especialização onde iniciam-se a discussão ou problema e, conseguinte soluções. 
As pesquisas feitas nesse período, independente da área de estudo, e autoria objetivam uma organização do serviço para melhoria da qualidade da assistência prestada.

$\mathrm{Na}$ área assistencial a enfermeira da SRA tem sua atuação melhor definida tecnicamente por executar atividades independentes, de forma autônoma, fundamentada nos conhecimentos e habilidades adquiridas durante sua formação profissional, e dependentes de interação com os demais elementos da equipe de saúde, no atendimento das necessidades do ser humano, tendo seu fim na conservação da integridade e promoção do bem estar. Talvez não seja do conhecimento de parte das enfermeiras, pelo envolvimento e satisfação, que essa atividade proporciona, como estão habilitadas a solucionar problemas, analisar e gerenciar novas situações já baseadas em uma metodologia, que nem sempre é explícita para ela em sua atividade diária.

Ao explicitar e utilizar um método científico a enfermeira sai dos limites físicos da SRA e passa a desenvolver sua atuação como enfermeira assistencial também no período anterior à cirurgia. Com as avaliações feitas nos períodos pré-operatório, de recepção do paciente em centro cirúrgico, intra operatório e avaliação pós-operatória é possível identificar o problema, planejar e implementar o cuidado, assim como avaliar os resultados (CASTELLANOS, 1978).

É evidente que esse método científico específico, assim como qualquer outro, precisa estar apoiado em uma filosofia institucional que viabilize a sua operacionalização.

Como exemplo de operacionalização a ser citado existe o Sistema de Assistência Perioperatório de Enfermagem (SAEP) que se utiliza de estratégias para sua realização.

É através da visita pré-operatória que a enfermeira identifica problemas, orienta o paciente e sua família segundo a necessidade sentida por ambos, se faz conhecer como profissional dessa área tão especifica e restrita do hospital e atua no relacionamento interprofissional.

Ao receber o paciente em centro cirúrgico, a enfermeira oferece a segurança física e apoio emocional, ações difíceis de serem definidas e transmitidas, mas sentidos pela enfermeira e paciente assim como reconhecidas e descritas por importantes pesquisas (BIANCHI, 1983; PANZA, 1977). Ao recepcioná-lo em centro cirúrgico dados relevantes para efetivação do ato anestésico cirúrgico também são coletados.

Constatado por vários autores entre eles SILVA (1989) foi observado que a necessidade de apoio emocional dos pacientes cirúrgicos é percebida pelos enfermeiros através da comunicação verbal e não verbal e que depende do significado que os enfermeiros atribuem a essa medida terapêutica, existindo facilidades pessoais para essa percepção como o conhecimento como conhecimento, empatia e formação religiosa, a maneira de ser do enfermeiro 
e dificuldades associadas a falta de preparo do enfermeiro, pacientes arredios,nível sócio-cultural dos pacientes e pacientes terminais além da falta de tempo e entrosamento, não colaboração da equipe, falta do profissional psicólogo na equipe, além de outros fatores. Citou também as facilidades institucionais exemplificada com a implantação de sistemas de assistência de enfermagem.

Após a recepção do paciente em centro cirúrgico a atuação da enfermeira de SRA no período transoperatório, inclui desde a conversa apropriada para a situação até a sua transferência para a maca no final da cirurgia na posição correta, passando pela monitorização dos sinais vitais, reação pupilar, textura da pele, monitorização cardíaca, funcionamento dos equipamentos, indução anestésica, e assistência d̀ intubação e extubação. Essa diversidade de procedimentos mostra também uma complexidade de conhecimentos exigidos para desenvolvê-los. Infelizmente, no Brasil, são poucas ou quase nenhuma instituição que possui, nesse período transoperatório, o profissional enfermeiro atuando (CASTELLANOS et al, 1986). Vários são os motivos, desde o desconhecimento dessa possibilidade até o alto custo que traria à instituição. Existe um recuo da enfermeira, que vivenciei através da minha experiência profissional, quando parte dessas atividades lhe pertenciam e foram concedidas ao pessoal de nível técnico, não ligado a equipe de enfermagem, por vários motivos incluindo aliviar a sobrecarga de serviço, ao invés de um melhor planejamento e organização das atividades, mesmo com a problemática de falta de funcionários e baixa remuneração.

Ao se efetuar a avaliação pré-operatória, recepção do paciente em cen. tro cirúrgico, e a assistência ao paciente em sala cirúrgica amplia-se a margem de segurança na avaliação do paciente $\mathrm{cm}$ SRA. Na evolução do paciente e implementação da assistência, nesse período de recuperação, deve-se contar com ajuda de índices (escores) para a avaliação e evolução de enfermagem associados aos levantamentos de riscos inerentes ao procedimento anestésico-cirúrgico e possíveis intercorrências do transoperatório, o que facilita a assistência de enfermagem mas, não diminui a complexidade da situação.

Vários autores ABRAHÃO et al, 1990; BELEZZE et al, 1989 ao fazerem uma análise crítica aos índices utilizados para avaliação, em particular ao proposto por ALDRETE; KROULIK (1970), questionam a pontuação préestabelecida como necessária para alta destes pacientes, que nem sempre significa uma fase sem complicações. Estudos realizados por BELEZZE et al 1989 , mostram que $35 \%$ de intercorrências surgiram nesse período, enfocando a singularidade do paciente, bem como a necessidade de enfermeiras, não só treinadas na execução do índice, qualquer que seja ele, mas fundamentalmente especializadas e alertas para agir com precisão e prontidão.

Com a avaliação pós-operatória feita, através da visita pós-operatória, 
a enfermeira da SRA tem como retroalimentar a assistência de enfermagem prestada ao paciente.

Independente do método adotado para o desenvolvimento da assistência de enfermagem, acreditamos que deva ser associado também a uma filosofia institucional. Por exemplo, na concepção sistêmica, o mundo é visto em termos de relação e de integração numa totalidade cujas estruturas resultam das interrelações e interdependências de suas partes (AVELAR; JOUCLAS, 1989). A SRA sob esta 6tica compõem-se de subsistemas importantes para o seu funcionamento (tecrológico, psico-social, estrutural, administrativo e de metas e valores).

Segundo AVELAR; JOUCLAS, 1989 apesar das interações existentes entre os subsistemas, o subsistema de metas e valores (crenças e valores individuais) permeiam todos eles, influenciando as ligações e interações que ocorrem e, até divergindo ou ignorando a estrutura formal do hospital e é desta interação que dependem os resultados esperados em SRA, ou seja, paciente consciente, com reflexos presentes, estabilidade de sinais vitais, permanência em ambiente terapêutico com recursos humanos e materiais necessários para evitar ou minimizar a exposição deste paciente aos riscos e complicações, inerentes a própria situação em que se encontra.

Pela possibilidade de abrangência da atuação da enfermeira em SRA, acreditamos numa perspectiva de melhor assistência ao paciente quando existir não só maior desenvolvimento na área da pesquisa, mas também quando as outras áreas de atuação (educação, administração e assistência) forem pautadas em métodos científicos propostos por essas pesquisas e em filosofias não só institucionais mas que estejam ancoradas em crenças e valores individuais.

PENICHE, A.de C.G. Including the nurse's role in the recovery room as the best assistance in perioperative period. Rev.Esc.Enf.USP, v.29, n.1, p. 83-90, Apr. 1995.

The article describes the nurse's role in the recovery room about assistance, educational, administrative and research areas. Those areas explored in our country to improve the assistance in perioperative period.

UNITERMS: Recovery room. Nurse's role in the recovery room.

\section{REFERÊNCIAS BIBLIOGRÁFICAS}

ABRAHÃO, M.S.M. et al. Análise crítica da escala de Aldrete e Kroulik como critério de alta na recuperaçño pós anestésica. Kev. Bras. Anestesiol., v. 40, p. 172, 1990. Supl. 12. 
ALDRETE, J.; KROULIK, D.A. A postonesthetic recovery score.Curr res. Anesth., v. 49, n. 6 , p. $924-33,1970$.

AVELAR, M.C.Q.; JOUCLAS, V.M.G. Centro Cirúrgico: sistema sócio-técnico estruturado.

Rev. Hosp. Adm. Saúde, v. 13, n.4, p. 152-55, 1989.

BELEZZE, M.J. et al. Incidência de complicaçoes na sala de recuperação pós anestésica. Rev. Bras. Anestesiol., v. 39, 1989. Supl. 11.

BIANCHI, E.R.F. Estudo exploratório sobre suspensão de cirurgia. A comunicação da suspensão e a reaçăo relatada pelo paciente frente ao fato. São Paulo, 1983, 74 p. Dissertação (mestrado) - Escola de Enfermagem, Universidade de São Paulo.

BIANCHI, E.R.F. et al. Estudo retrospectivo da pesquisa de enfermagem em centro cirúrgico. Enfoque, v. 16, n. 3, p. 75-7, 1988.

CASTELI.ANOS, B.E.P. Aplicacão do processo de enfermagem ao cuidado do paciente na unidade de centro cirúrgico. Rev. Esc. Enf. USP.., v. 12, n.3, p. 170-86, 1978.

CASTELLANOS, B.E.P. et al. Assistência de enfermagem no período transoperatório. Enfoclue, v. 14, n.3, p. 7-11, 1986.

FARMER, ( $x$. The role of the anaesthetic nurse. NAT NEW'S, v. 22. n.11, p. 10-2, 1985.

FRANILLIN, B.M.; FRAULINI, E.K. Development of the postanesthesia care unit. In: Frauline K.E.: After anesthesia: a guide for Pacu, ICU, and medical-surgical nurses. California, Appleton \& Longe, 1987. cap. 1, p. 33-15.

FRALILINI. E.K. After anesthesia. A guide for Pacu, ICU and medical-surgical nurses. California, Appleton \& Longe. 1987, cap. 2, p. 19-24.

LITWACK, K. Carier development for the pacu nurse. Curr. Rev. Post. Anesth Care Nurses., v. 8, n. $11,1,57-64,1989$

MINZONI. M.A. A profissão de enfermagem e seu significado. Enf. Atual. v. 3. n. 13, p. 89, 1980.

NOCITE. J.R. O período de recuperação pós-anestésica. Rev. Bras. Anestesiol.. v. 37, n.3, p. $161-67,1987$.

NOGUEIRA. M.d. de A. A pesquisa em enfermagem no Brasil: retrospectiva histórica Rev. Esc. Enf. LISP., v. 16, n.1, p. 17-26, 1989. 
PANZA. A.M.M. Efeito da visita pré-operatória da enfermeira do centro cirúrgico sobre o estresse do paciente no pré-operatório, no dia da cirurgia e no pós-operatório. São Paulo, 1977, 75 p. Dissertação (mestrado) - Escola de Enfermagem, Universidade de São Paulo.

SILVA, A. Percepção dos enfermeiros a respeito do apoio emocional oferecido aos pacientes cirúrgicos. Săo Paulo, 1989. 89p. Dissertação (mestrado) - Escola de Enfermagem, Universidade de Săo Paulo. 